\title{
Erratum to: Effect of Composition and Structure of Metal Oxide Composites Nanostructured on Their Conductive and Sensory Properties
}

\author{
G. N. Gerasimov ${ }^{a}$, V. F. Gromov ${ }^{a}$, M. I. Ikim ${ }^{a, ~ *, ~ a n d ~ L . ~ I . ~ T r a k h t e n b e r g ~}{ }^{a, b}$ \\ ${ }^{a}$ Semenov Federal Research Center for Chemical Physics, Russian Academy of Sciences, Moscow, Russia \\ ${ }^{b}$ Moscow State University, Moscow, Russia \\ *e-mail: ikim1104@rambler.ru
}

Received December 14, 2021; revised December 14, 2021

The surname of the fourth author should read L. I. Trakhtenberg.

DOI: $10.1134 /$ S1990793121310018

The original article can be found online at https://doi.org/10.1134/S1990793121060038

The original article has been corrected. 